\title{
Adaptive Approach to Structure And Properties Forming in Niobium Alloyed Pipe Steels
}

\author{
Eduard Golubchik \\ Material Processing Technologies Department \\ Nosov Magnitogorsk State Technical University \\ Magnitogorsk, Russia
}

\author{
Marina Polyakova \\ Material Processing Technologies Department \\ Nosov Magnitogorsk State Technical University \\ Magnitogorsk, Russia \\ m.polyakova-64@mail.ru
}

\begin{abstract}
The results of research aimed at structure formation in niobium alloyed steels for pipe production by means of dynamic recrystallization control during hot rolling at a wide strip mill are shown. Influence of deformation, time and temperature parameters in the continuous roughing train of a wide strip hot rolling mill, on the microstructure of niobium alloyed steels and the level of their mechanical properties is studied. It is shown that within the temperature range of 1000 $1050^{\circ} \mathrm{C}$ in steels $\mathrm{X52}-\mathrm{X} 70$ grade beside intensive dynamic recrystallization, one can see secondary recrystallization as well. From the obtained data it is evident that niobium alloyed pipe steels with lower carbon content $0.06-0.08 \% \mathrm{C}$ mechanical properties are ensured by hard solution strengthening mechanism of Mn combined with $\mathrm{Ni}$ and $\mathrm{Cr}$. Optimal both temperature and rate parameters of hot deformation during rolling are determined. It leads to increasing ductility basically toughness of niobium contained steels for pipes.
\end{abstract}

Keywords—structure formation; impact strength; dynamical recrystallization; hot rolling; niobium alloyed steels

\section{INTRODUCTION}

Oil and gas pipelines of new generation developed at present, are characterized by higher economical and operational efficiency and reliability. The required set of properties is obtained by the use of advanced pipe steels, which combine high strength and cold resistance with high welding characteristics. As a rule, these steels must be microalloyed with carbonitriding forming elements $(\mathrm{Nb}, \mathrm{V})$ [1-3]. To guarantee high operational integrity of metal for gas and oil pipes, it is necessary to provide the following parameters of metal: resistance to brittle failure in the operating temperature range, high resistance to crack propagation, resistance to hostile environment influence and good welding characteristics. One of the most efficient methods of hot forming for such steels is controlled rolling $[4,5]$. This method makes it possible to obtain high strength low alloyed rolled product in hot-rolled state with high cold resistance and impact strength value at low temperatures. Besides achieving the required shape and size of a rolled product, the main aim of controlled rolling is obtaining a specific microstructure. It can provide a unique set of

The research corresponds with realization of complex project (contract 02.G25.31.0040) and was carried out in accordance with the government order of the Ministry of Education and Science of the Russian Federation (contract 11.1525.2014) mechanical and physical properties due to solid-solution strengthening, grain refining, precipitation hardening, dislocation, sub-grain and texture hardening of metal, immediately after the hot rolling process $[6,7]$.

It is common practice to use electric-welded helical pipes and single-joint welded pipes produced by high-frequency welding for construction of main oil and gas pipelines from X52-X70 grade pipes $[8,9]$. Requirements to mechanical characteristics of the base metal for pipes are regulated by ISO 3183 and API 5L standards. One of the most significant characteristics of rolled metal products for pipe manufacture is impact strength. However, there is a recent trend to carry out the impact bending test of specimen with a V-type notch at temperatures of $-20^{\circ} \mathrm{C}$ and even lower instead of samples with a U-type notch. This offers a better understanding of steel resistance to brittle fracture. In particular for the rolled products produced in accordance with EN 10025-4 standard, the test of impact energy values is carried out for Sharpy specimen at the temperatures of $-20^{\circ} \mathrm{C}$ or $-50^{\circ} \mathrm{C}$. In addition, for structural metal structures the amount of viscous component is controlled by the drop-weight test at the temperature of $-20^{\circ} \mathrm{C}$ and by the impact bending test of samples with a V-type notch at temperature of $-60^{\circ} \mathrm{C}$. The requirements to mechanical properties of rolled products are formed taking into account the influence of pipe constraints and the pipeline operating conditions. This results in higher requirements to mechanical properties of coiled stock. Specifications stipulate the set of mechanical properties corresponding to X70 grade: both for transverse test specimen and longitudinal specimen as well as for specimen taken at the angle of $30^{\circ}$ to the rolling direction. Besides, cold resistance is regulated for drop-weight test, where the temperature of ductile-brittle transition must be below $-30^{\circ} \mathrm{C}$, and the amount of viscous grain must exceed $80 \%$.

Thus at present it is often necessary to form higher toughness characteristic in steels and at the same time provide the required level of mechanical properties of hot rolled metal product used for pipe manufacture, which calls for development of new concepts of operational control of structure formation in processes of hot plastic deformation. 


\section{THEORETICAL BASICS}

Practical experience all over the world shows that coiled and flat stock from low carbon microalloyed $(\mathrm{V}, \mathrm{Nb}, \mathrm{Ti}, \mathrm{Mo}$ etc.) pipe steel produced by controlled rolling technology has significant anisotropy of properties [10-12]. It is due to the crystal rolling texture (usually $\{112\}[110]$ ) and microstructure formation characterized by certain elongation in the rolling direction. The lowest level of strength properties is noted for test specimen taken at an angle of $45^{\circ}$. The set of properties of the coiled stock with the thickness of $12-14 \mathrm{~mm}$ with the minimum alloying level providing steel weldability, is achieved during formation of fine-grain ferrite-bainite microstructure. For steels with ferrite-bainite microstructure unlike traditional steels with ferrite-pearlite microstructure, characteristics of impact strength and cold resistance are lower for specimen taken at an angle than for specimen taken transversely. This can be explained by the nature of bainite strips formation, which is occupied the regions of the former austenite grains. To reduce the level of center segregation in steel, it is necessary to limit in it the content of elements with high segregation factor, such as $\mathrm{C}$ and $\mathrm{Mn}$. Besides, high level of mechanical properties can be achieved by means of transition from ferrite-pearlite structure to ferrite-bainite one and by application of such advanced ways of strength improvement as grain refining and precipitation hardening.

Traditional controlled rolling provides complete recrystallization of austenite during the roughing stage of plastic deformation and it does not provide any recrystallization during the finishing stage of controlled rolling, which is determined by the rolling temperature range. On the roughing stage in the temperature range of austenite recrystallization, the width of which is determined mainly by niobium content in the steel, it is necessary to provide maximum refining of the initial austenite grain. This is achieved by repetitive recrystallization after each reduction. During coiled stock production, controlled rolling is, as a rule, combined with accelerated cooling and includes the following stages. Slab heating. Reheat temperature of slabs must be high enough to provide transition of microalloying elements into solid solution and is determined by the element content (mainly by the content of niobium, carbon and nitrogen). To prevent the austenite grains from excessive growth during heating, microaddition of titanium is used (usually about $0.015-0.030$ of the mass \%), as its nitrides suppress grain growth during heating. Reheat temperature of slabs at temperatures of $\mathrm{T}_{\mathrm{n}}=$ $1220 \pm 20^{\circ} \mathrm{C}$ provides transition of up to $0.07 \%$ of $\mathrm{Nb}$ into solid solution, when the content of $\mathrm{C}$ in steel is $\approx 0.07 \% \mathrm{C}$ and nitrogen content is $\leq 0.008 \% \mathrm{~N}_{2}$. To provide complete and secure solution of $\mathrm{Nb}$ from $\mathrm{NbC}$ rather than $\mathrm{Nb}(\mathrm{C}, \mathrm{N})$, it is recommended to maintain nitrogen content in steel $\leq 0.006 \%$ $\mathrm{N}_{2}$. Nonuniform size of austenite grain results in nonuniform size of ferrite grain or to formation of coarse regions of upper bainite instead of ferrite-pearlite structure or the structure of granular bainite due to the stability improvement of coarse grain austenite. To prevent nonuniform size of austenite, the optimum mode of rough rolling must include at least four final passes with $15-25 \%$ reduction with the increase of reduction by the final pass before cooling. Finish rolling. If deformation terminates in $\gamma$ - region, austenite with high unit effective surface (high specific density of grain boundaries, deformation bands, twinned crystals, dislocation structures, etc.) is formed, thus increasing the number of places of ferrite origin and refining of its grains. In traditional approach, initial deformation during finish rolling takes place in $\gamma$-region with gradual transition to $(\gamma+\alpha)$-region. This provides the increase of strength and toughness. It is important that crystal structure is formed in ferrite, which results in formation of characteristic bend with "splitting" and improves the cold resistance of the rolled product. Accelerated cooling. The state of hot-deformed austenite prior to finish rolling determines the forming of uniform structure of the final rolled product. During the roughing stage of controlled rolling, uniform austenite structure made up of equiaxial recrystallized grains is formed due to the fact that complete recrystallization takes place in the first rolling stands, dynamic recrystallization takes place in the rolling stands of continuous group of the roughing train, and secondary recrystallization takes place on the outgoing roller table.

Industrial wide strip hot rolling mills are usually designed in such a way that, end rolling stands of the roughing train are usually united into a continuous group, which are kinematically rigidly connected with each other. As a result, recrystallization during rolling of niobium alloyed steels can be incomplete, which, in its turn, contributes to nonuniformity of austenite structure and to decreasing of toughness of the final rolled product. The presence of equiaxial and deformed austenite grains prior to finish rolling results in the nonuniform grain size of the microstructure of the final rolled product and in deterioration of ductility and toughness characteristics. That is why, when selecting the scheme of deformation, it seems reasonable to take into account the pause between the passes. Thus, in order to be able to control the structure forming process providing a high level of toughness characteristics in niobium alloyed pipe steels on the roughing stage of controlled rolling, it is necessary to apply the strategies of adaptive control of dynamic recrystallization processes by means of operational thermal-deformational influence in the final passes of the roughing train of the hot rolling mill.

\section{EXPERIMENTAL PART}

The main aim of rolling of the X52 - X70 steel grades under study is to extend the region of complete austenite recrystallization and to slow down the growth of recrystallized grains. Two chemical compositions introduced in Table I were used in the experiments. Composition A is noted for low carbon content $(\mathrm{C}=0.06 \%)$, additions of nickel $(\mathrm{Ni}=0.24 \%)$, copper $(\mathrm{Cu}=0.17 \%)$ and high niobium content $(\mathrm{Nb}=$ $0.063 \%)$. Composition $\mathrm{B}$ is characterized by higher carbon content $(\mathrm{C}=0.08 \%)$ and lower niobium content $(\mathrm{Nb}=0.031 \%)$.

The research group carried out a number of experiments to find out the influence of deformation, time and temperature parameters in the continuous roughing train of a wide strip hot rolling mill, on the microstructure of niobium alloyed steels and the level of their mechanical properties. The research complex GLEEBLE 3500 was used to carry out the simulation. 
TABLE I. COMPOSITION OF EXPERIMENTAL HEATS, $\%$

\begin{tabular}{|c|c|c|c|c|c|c|c|c|c|c|c|c|c|c|c|}
\hline Composition & $\mathbf{C}$ & $\mathbf{S i}$ & $\mathbf{M n}$ & $\mathbf{S}$ & $\mathbf{P}$ & $\mathbf{C r}$ & $\mathbf{N i}$ & $\mathbf{C u}$ & $\mathbf{N}_{\mathbf{2}}$ & $\mathbf{A l}$ & $\mathbf{N b}$ & $\mathbf{V}$ & $\mathbf{T i}$ & $\mathbf{C}_{\text {equivalent }}$ \\
\hline $\mathbf{A}$ & 0,06 & 0,24 & 1,55 & 0,003 & 0,008 & 0,03 & 0,24 & 0,17 & 0,006 & 0,037 & 0,063 & 0,004 & 0,020 & 0,36 \\
\hline $\mathbf{B}$ & 0,08 & 0,53 & 1,43 & 0,004 & 0,010 & 0,14 & 0,05 & 0,04 & 0,005 & 0,034 & 0,031 & 0,006 & 0,016 & 0,36 \\
\hline
\end{tabular}

Specimen of Diameter $\times$ Length $=10 \times 80 \mathrm{~mm}$ size were heated to $1200^{\circ} \mathrm{C}$ for $180 \mathrm{sec}$., and temperature equalization along the cross-section took $\approx 300 \mathrm{sec}$. Further thermal and deformational treatment was carried out in the following way: they were cooled to the temperature of the deformation point $T_{i}$ in the range of $900-1050{ }^{\circ} \mathrm{C}$ at the rate of $5{ }^{\circ} \mathrm{C} / \mathrm{sec}$.; deformation for three passes with the total degree of deformation $\varepsilon_{\Sigma}=45-65 \%$ and the rate of deformation in the final pass $\xi_{i}=(0.6-1.2) \mathrm{c}^{-1}$. Then the specimen were cooled at the rate of $80{ }^{\circ} \mathrm{C} / \mathrm{sec}$. immediately after deformation, and after holding at the temperature of deformation within 5-60 sec. Interdeformation pause $t_{i}$ was chosen on the basis of assumption of constant time in the continuous group of rolling stands on the assumption of free rolling (without tension or support/backing). To compare the influence of alloying composition on the structural state of hot-deformed austenite, the research group carried out the simulation of rolling process for composition $\mathrm{B}$ with the total deformation ratio of $65 \%$ within the temperature range of $900-1050^{\circ} \mathrm{C}$ and the rate of deformation in the final pass $\xi_{i}=(0.6-1.2) \mathrm{c}^{-1}$.

When the research group studied the influence of temperature change on the preliminary stage of controlled rolling on formation of austenite structure of niobium alloyed steels of both compositions, the specimen after austenitization at the temperature of $1200^{\circ} \mathrm{C}$ were deformed for three degrees of reduction in the range of $\varepsilon_{i}=26-31 \%$ at the temperature range of $T_{i}=980-1050^{\circ} \mathrm{C}$ with the rate of deformation of $\xi_{i}=$ $(0.46-0.58) \mathrm{c}^{-1}$. The pause between the passes was $8-11$ seconds, the cooling rate of the specimen in the interdeformation pauses is described by a linear function. After deformation the specimen was cooled to the temperature of $900{ }^{\circ} \mathrm{C}$ at the rate of $1{ }^{\circ} \mathrm{C} / \mathrm{sec}$. The microstructure of metal was studied on polished specimen prepared by cutting of the deformed specimen along the compression axis. To find out the former boundaries of austenite grains, the polished specimen were hot pickled in the solution of picric acid. Optical microstructures were obtained by means of Meiji Techno IM7000 microscope.

\section{RESULTS AND DISCUSSION}

In Fig. 1, one can see an image of a characteristic austenite grain of steel with the composition a processed at the temperature of $1050{ }^{\circ} \mathrm{C}$ with the deformation ratio of $65 \%$ and the rate of deformation of $1.2 \mathrm{c}^{-1}$ with the post deformation pause of $10 \mathrm{sec}$.

Analysis of experimental results showed that within the temperature range of $1000-1050^{\circ} \mathrm{C}$ in all the steels under study beside intensive dynamic recrystallization, one can see secondary recrystallization as well.

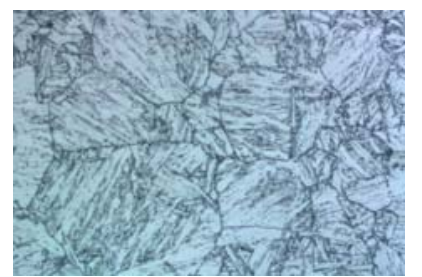

Fig. 1. The microstructure of austenite of steel with the composition A processed in the following way: temperature of deformation $1050^{\circ} \mathrm{C}$, deformation ratio $65 \%$, deformation rate $1.2 \mathrm{sec}-1$, post deformation pause 10 sec. $\times 500$

When the recrystallization temperature decreases, recrystallization processes tend to slow down increasing the interval after which primary and secondary recrystallization of austenite start. For composition B, dynamic recrystallization within the analyzed temperature range of $900-1050^{\circ} \mathrm{C}$ finishes completely within $10 \mathrm{sec}$, however, fine equiaxial austenite grain is formed as a result. When the deformation temperature goes down, grain area decreases from 513 to $92 \mu \mathrm{m}^{2}$.

In the steel with higher niobium content (composition A) for this time interval after deformation at the temperature of $900-1000^{\circ} \mathrm{C}$, primary recrystallization did not complete in full and the structure consisted of a mixture/combination of equiaxial and deformed (elongated along the rolling direction) austenite grains. When the time of isothermal holding was increased to $30 \mathrm{sec}$, primary recrystallization of austenite completed and secondary recrystallization of austenite developed in all steels. The increase of post deformation isothermal holding to $60 \mathrm{sec}$. resulted in further development of secondary recrystallization of austenite. When changes were introduced into the deformation-and-rate rolling schedule, the number of coarse grains gradually decreased, and the share of ferrite grains with the diameter less than 7 micrometers increased from 30 to $57 \%$. It was also found that the increase of the deformation ratio and the shift of the deformation scheme into the region of lower temperatures contribute to the refining of ferrite grain from 3.73 to 3.08 micrometer.

When the specimen were studied though the transmission electron microscope, the research group found the presence of particles of niobium carbonitrides $\mathrm{Nb}(\mathrm{C}, \mathrm{N})$ in two forms: particles formed in austenite and interphase ones formed at the front of $\gamma \rightarrow \alpha$ transformation. One ferrite grain contains particles of the both forms with different crystallographic orientation.

Table II and Fig. 2 offer the obtained results of mechanical properties of steel rolled at a wide strip hot rolling mill in the tested rolling schedules. 


\begin{tabular}{|c|c|c|c|c|c|c|c|c|}
\hline \multirow{2}{*}{ Steel grade } & \multirow{2}{*}{$\begin{array}{c}\text { Specimen } \\
\text { orientation }\end{array}$} & \multirow{2}{*}{ Cutting direction } & \multicolumn{6}{|c|}{ Impact strength $\mathrm{KCV}, \mathrm{J} / \mathrm{cm}^{2}$ at different temperatures } \\
\hline & & & $+20^{\circ} \mathrm{C}$ & $0^{\circ} \mathrm{C}$ & $-20^{\circ} \mathrm{C}$ & $-40^{\circ} \mathrm{C}$ & $-60^{\circ} \mathrm{C}$ & $-80^{\circ} \mathrm{C}$ \\
\hline \multirow{3}{*}{ Composition A } & $90^{\circ}$ & \multirow{2}{*}{ From the surface } & 309 & 262 & 267 & 273 & 250 & 208 \\
\hline & $30^{\circ}$ & & 349 & 355 & 330 & 304 & 156 & 74 \\
\hline & $90^{\circ}$ & $1 / 2$ in thickness & 318 & 274 & 238 & 194 & 142 & 55 \\
\hline
\end{tabular}

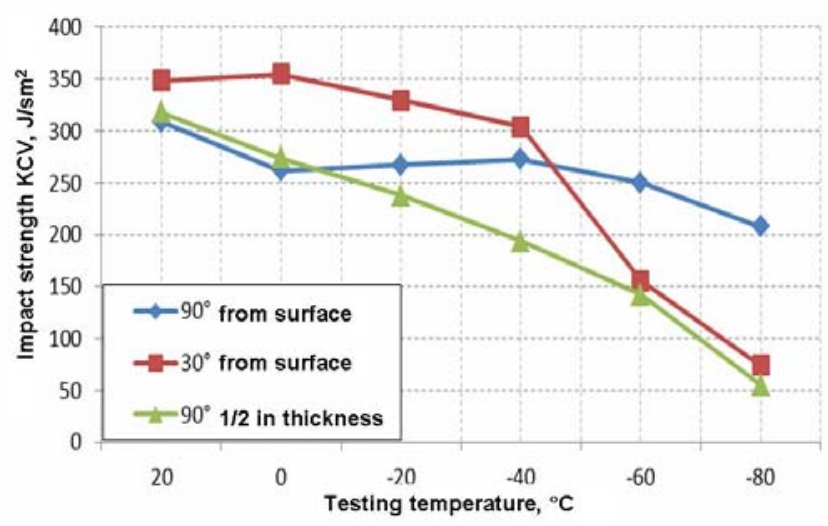

Fig. 2. Results of the series of Sharpy impact tests

From the obtained data, it is evident that niobium alloyed pipe steels with lower carbon content 0.06-0.08\% C mechanical properties are ensured by hard solution strengthening mechanism of $\mathrm{Mn}(1.40-1.55 \%)$ combined with $\mathrm{Ni}(0.10-0.20 \%)$ and $\mathrm{Cr}(0.10-0.20 \%)$. At the same time, the ferrite-bainite structure is obtained which guarantees high levels both yield strength and tensile strength. Higher niobium content $(0.050-0.065 \%)$ impedes austenite recrystallization which leads after finishing deformation to austenite structure formation with a plenty of new phases grains nucleation. Hence, this ensures the small size of ferrite grains. It besides niobium by forming carbonitride ensures higher steel strength properties due to dispersion hardening mechanism.

In general, mechanical properties of samples cut from one direction after tensile testing is distributed satisfactorily uniformly along the strip length. Maximum strength indicators and, hence, lower elongation are observed in samples cut in the transversal direction relatively to strip length. The obtained data prove that impact strength is high up to $-60^{\circ} \mathrm{C}$ temperature (more than $90 \mathrm{~J} / \mathrm{cm}^{2}$ ). But at the temperature lower than $-20^{\circ} \mathrm{C}$ abrupt decrease both impact strength and viscous share in sample fracture is observed. Besides it is found that rolled strip cold-shortness threshold $\mathrm{KCV} \geq 85 \%$ occurs at temperature $0^{\circ} \mathrm{C}$, below which abrupt decrease both impact strength and viscous share is observed in the case of manufacturing in accordance with the regulated single deformation degrees.

\section{CONCLUSION}

The obtained results were used in development of technology for the manufacture of coiled stock from niobium alloyed steel with the thickness of $20.0 \mathrm{~mm}$ with the guaranteed compliance with requirements to the impact strength $\left(\mathrm{KCV}^{-40} \geq 40 \mathrm{~J} / \mathrm{cm}^{2}\right)$ intended for the production of electric-welded pipes $530 \mathrm{~mm}$ in diameter and $16.5 \mathrm{~m}$ in length for construction of South-Tambeisk gas condensate field (Russia). Application of the advanced technology made it possible to obtain in the coiled stock of increased thickness a combination of high strength $\left(\sigma_{\mathrm{T}} \geq 530 \mathrm{MPa}, \sigma_{\mathrm{S}} \geq 610 \mathrm{MPa}\right)$, impact strength $\left(\mathrm{KCV}^{-20} \geq 250 \mathrm{~J} / \mathrm{cm}^{2}\right)$ and cold resistance achieved due to the formation of even fine ferrite-bainite microstructure of steel.

\section{REFERENCES}

[1] H. Dong, X. Sun, W. Hui, S. Zhang, J. Shi and M. Wang, "Grain Refinement in Steels and the Application Trials in China", ISIJ Int., vol. 48, No. 8, pp. 1126-1132, 2008

[2] S. Hong, S. Lim, H. Hong, K. Lee, D. Shin and K. Lee, "Effects of Nb on Strain Induced Ferrite Transformation in C-Mn Steel", Mater. Sci. Eng. A, vol. A355, pp. 241-248, 2003.

[3] H. Yada, C.-M. Li and H. Yamagata, "Dynamic Transformation during Hot Deformation in Iron-Nickel-Carbon Alloys", ISIJ Int., vol. 40, No. 2, pp. 200-206, 2000.

[4] E. Golubchik, V. Telegin, I. Vasilyev, A. Arkhandeev and V. Ryabchikov, "The development of spar bands production technology using controlled rolling in OJSC «MMK», Steel, No 7, pp.35-38, 2012.

[5] P. Hurley, B. Muddle and P. Hodgson, "Nucleation Sites for Ultrafine Ferrite Produced by Deformation of Austenite During Single-Pass Strip Rolling", Metall. Mater. Trans. A, vol. 32A, pp.1507-1517, 2001.

[6] M. Hickson, P. Hurley, R. Gibbs, G. Kelly and P. Hodgson, "The Production of Ultrafine Ferrite in Low-Carbon Steel by Strain- Induced Transformation", Metall. Mater. Trans. A, vol. 33A, pp. 1019-1026, 2002.

[7] H. Dong and X. Sun, "Deformation Induced Ferrite Transformation in Low Carbon Steels", Current Opinion in Solid State and Materials Science, vol. 9, pp. 269-276, 2005.

[8] L. Yao, X. Zhao and S. Zhao, "Steel Plate with Yield Strenght of 800mpa Grade and Low Weld Cracking Sensivity, and Manufacture Method Thereof", EP Patent 2,218,801. 2010

[9] A. Bodin, "Process and Device for Producing a Ferritically Rolled Sheet Strip", WO Patent 9,929,446. 1999

[10] S. Denisov, P. Smirnov, E. Golubchik and P. Stekanov, "Manufacture Method for Low Alloyed Pipe Steel of X60 Strength Grade", SheetR.U. Patent 2,458,156. 2011

[11] S. Denisov, P. Smirnov, E. Golubchik and E. Braichev, "Manufacture Method for Low Alloyed Pipe Steel Sheet", R.U. Patent 2,458,754. 2011

[12] S. Denisov, P. Smirnov and E. Golubchik, "Manufacture Method for Low Alloyed Pipe Steel Sheet of X70 Strength Grade" R.U. Patent $2,458,751.2011$ 
